\title{
The Extinction or Resurrected Human Specie
}

\author{
Julie Rammal* \\ George Washington University, USA \\ *Corresponding Author: Julie Rammal, George Washington University, USA
}

Received: May 24, 2019; Published: June 21, 2019

DOI: 10.31080/ASOR.2019.02.0069

We have come to a time, where we must choose our paths. The human specie can only continue with a shift in consciousness, increase in spirituality, mastery of oneself, and change of heart. The rapid evolution of the human specie has torn the body, mind, and spirit connection resulting in increase medical, mental and physical care facilities. However; none of the facilities look at the human specie as a body, mind and spirit.

Through history, change took time. The first apes appeared approximately 6-7 million years ago, followed by an evolution in tool making that occurred around 3.3. million years ago. Around 2.8-2.75 million years ago, the oldest remains of the genus Homo appeared, and humans only appeared around 315,000 years ago. We are currently evolving much quicker than history has recorded the human evolution. This rapid transition in the human specie reflects what might be labelled as a boost in intelligence, however; we did not realize that a mind needs a body and spirit to exist or it will not exist in the right form. It will be disfigured. As a result, we see a more "mental era," which has resulted to stress, depression, and numerous mental illnesses. As our minds quickly evolved we became detached to ourselves, and as a result for the first time in history we have a high rate of mental, physical and emotional issues. Simple questions arise as how should we eat? Sleep? Socialize? We have dis-connected ourselves from the source of what life has brought us here to do.

To survive the next era, one must choose to master and resurrect their body, mind and spirit; or the human specie will slowly dissolve. In history, our connection to our consciousness, religions, our faiths have changed numerous times. Today, we come back to learning from our ancestors the knowledge, messages that they have sent us in order to survive the future. We cannot see clearly as many of us are not truly connected with the universe.

In ancient Egypt the soul was extremely important, however; today our soul is generally not cared for. Many of us are not living our life's purpose, and as a result we are not in harmony with our journey which creates harsh experience, unhappiness, and struggles. To survive the future, we must master ourselves. We have been thrown into a world where technology, inventions were created without following the universal law of earth. The universal law of the earth is simple: love, gratitude, compassion, and helping mother earth.

With our greed of discovering our mind, we began to separate ourselves from nature and the divine. For example, in 1879 the first light bulb was created, a splendid idea, however; we did not know that deviation in light affects our entire circadian rhythms. Why would we need light, when light was free? Another example, the first car was created in 1885/1886, the first plane appearing in 1903 , and the first computer was created in 1936. Was the intention of all this built to spread love? As it has only spread more fear, hardships, and dis-connection, and has now forced our body, mind and spirit to adapt at alarming rates to the life we are living.

We did not let evolution take its natural time to change us, instead we have tried to change evolution. We have gone against the laws of the universe, and nature. The human specie changed to having more: fear, greed, addictions, obsessions, ego, losing or having a de-attached connection to their soul, as we move away from the source. Most people are living a painful life, in which we need to universally re-connect and heal ourselves and heal the planet. Change will start, once mastery of ourselves is spread, and we live our soul's purpose. Most of us have become crystalized in body, mind and spirit. We do not know how to sleep, eat, train, think or live. We have forgotten that we are human beings, before what we have created ourselves to be. Our body and mind can not exist without a soul. If we do not have a soul or are dis-connected we become like a machine. Therefore, as we advance more rapidly, we are only advancing to self destruction. The wisest one's will follow the shift in consciousness and master themselves. If we do not have this shift in consciousness the human specie will self destruct itself and earth, and will continue to spread more fear, greed and ego.

In conclusion, to survive the next era and be ahead of the change it is in our interest to live within us and know ourselves. We should stop trying to copy each other, or look like each other, rather we should solidify ourselves, shift our consciousness connection, in- 
crease our spirituality, and to care for the soul. When we re-open our hearts, and unblock ourselves we can receive the universe's abundance. The quicker we begin to realize and execute that we are all universal humans, and come together as one, we will have a more positive impact to change the destructive world that we have created. Nature does not need us, but we need nature to survive.

Volume 2 Issue 7 July 2019

(c) All rights are reserved by Julie Rammal. 